\title{
Effect of a nutrition education programme on clinical status and dietary behaviours of adults with type 2 diabetes in a resource- limited setting in South Africa: a randomised controlled trial
}

\author{
Jane W Muchiri ${ }^{1, *}$, Gerda J Gericke ${ }^{1}$ and Paul Rheeder ${ }^{2}$ \\ 'Department of Human Nutrition, Faculty of Health Sciences, University of Pretoria, Private Bag X323, Pretoria \\ 0001, South Africa: ${ }^{2}$ The School of Medicine, Department of Internal Medicine, Faculty of Health Sciences, \\ University of Pretoria, Pretoria, South Africa
}

Submitted 7 February 2014: Final revision received 16 February 2015: Accepted 18 February 2015: First published online 15 April 2015

\begin{abstract}
Objective: To evaluate the effect of a participant-customised nutrition education programme on glycated $\mathrm{Hb}\left(\mathrm{HbA}_{1 \mathrm{c}}\right)$, blood lipids, blood pressure, $\mathrm{BMI}$ and dietary behaviours in patients with type 2 diabetes mellitus.

Design: A randomised controlled trial. The control group ( $n$ 41) received education materials. The intervention group ( $n$ 41) received the same education materials and participated in eight weekly $(2-2.5 \mathrm{~h})$ group nutrition education sessions and follow-up sessions. Outcomes were assessed at 6 and 12 months. An intention-to-treat analysis was conducted. ANCOVA compared the groups (adjustments for baseline values, age, sex and clinic).

Setting: Two community health centres, Moretele sub-district (North West Province), South Africa.

Subjects: Adults (aged 40-70 years) with type 2 diabetes, $\mathrm{HbA}_{1 \mathrm{c}} \geq 8 \%$.

Results: Differences in $\mathrm{HbA}_{1 \mathrm{c}}$ (primary outcome) were $-0.64 \%(P=0.15)$ at 6 months and $-0.63 \%(P=0.16)$ at 12 months in favour of the intervention group. Starchy-food intake was significantly lower in the intervention group, $9 \cdot 3 \mathrm{v} \cdot 10 \cdot 8$ servings/d $(P=0.005)$ at 6 months and $9.9 v .11 .9$ servings/d $(P=0.017)$ at 12 months. Median energy intake was significantly lower in the intervention group at 12 months $(5988 v .6946 \mathrm{~kJ} / \mathrm{d}, P=0 \cdot 017)$. No significant group differences in BMI, lipid profile, blood pressure and intakes of macronutrients, vegetables and fruits were observed.

Conclusions: Nutrition education was not efficacious on $\mathrm{HbA}_{1 \mathrm{c}}$; however, it improved specific dietary behaviours. Group education and hands-on activities appeared to contribute to the improvement. Optimal goal setting and self-efficacy training/assessment could benefit future nutrition education programmes for people with type 2 diabetes mellitus in resource-limited settings.
\end{abstract}

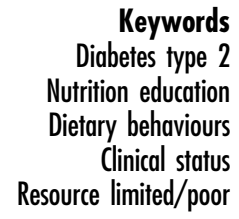

Keywords

Nutrition education

ietary behaviours

Resource limited/poor
The prevalence of type 2 diabetes mellitus (T2DM) is rising rapidly globally and is considered a public health problem $^{(1)}$. The developing countries are expected to be more affected by the problem, with the Africa region predicted to have the largest proportional increase in the number of adults with T2DM by $2030^{(2)}$. In South Africa T2DM is a significant health and economic burden ${ }^{(3)}$. A prevalence of $6.5 \%$ was reported for South Africa in 2011 in the Diabetes Atlas (5th edition) ${ }^{(4)}$ and levels of $8.5-8.8 \%$ reported for a population in a rural resourcelimited area ${ }^{(5)}$.

Individuals of low socio-economic status are among the groups noted as experiencing worse long-term diabetes management outcomes ${ }^{(6-8)}$. This problem is attributed to more socio-economic barriers to self-care, including limited access to continuous quality care ${ }^{(9)}$. Barriers to selfcare may be particularly apparent for dietary self-care ${ }^{(10)}$, an area cited as among the most difficult of diabetes selfcare areas ${ }^{(11)}$. Poor dietary adherence is a recognised problem in people with $\mathrm{T}_{2} \mathrm{DM}^{(12-14)}$. The barriers associated with the problem are also well documented in the literature ${ }^{(12,14,15)}$, even for individuals in a resource-limited setting in South Africa ${ }^{(14)}$. Therefore, people from resource-limited settings who are living with diabetes are an important target group for interventions - particularly dietary interventions. 
Diabetes self-management education (DSME) empowers the person with diabetes with the knowledge, skills and motivation that are needed to perform appropriate self-care ${ }^{(16)}$. DSME has been shown to be effective in improving knowledge, self-care behaviours, glycaemic control and other health outcomes ${ }^{(17,18)}$. Medical nutrition therapy (MNT) is an integral component of $\operatorname{DSME}^{(19)}$. MNT, both as an independent variable and in combination with other components of DSME, has been shown to be effective in improving health outcomes in individuals with diabetes $^{(20)}$. However, despite the established role of MNT in enhancing diabetes control, its contribution to diabetes management in Africa, including South Africa, is not well established. There is a paucity of data on structured nutrition education (NE) programmes and their effects on dietary and health outcomes in individuals with diabetes. Education that addresses the needs, abilities and interests of participants is considered effective in improving health and related outcomes ${ }^{(21,22)}$.

The purpose of the present study was to implement an NE programme that was planned based on assessed needs and to evaluate its effect on glycated $\mathrm{Hb}\left(\mathrm{HbA}_{1 \mathrm{c}}\right)$, BMI, blood pressure, blood lipids and dietary behaviours of adults with T2DM in a resource-limited setting.

\section{Methods}

\section{Study setting}

The study was conducted in two community health centres (CHC) in Moretele sub-district, North West Province, South Africa. The CHC are primary health-care clinics that are nurse managed. General physicians conduct consultations three times per week with referred patients. Patients with diabetes visit the clinics on a monthly basis for routine blood glucose monitoring and collection of medication. Health education at the $\mathrm{CHC}$ (including nutrition) is mainly the work of nursing professionals, since one dietitian serves the whole sub-district. There is no structured diabetes education offered at the CHC. Moretele sub-district is characterised by a high unemployment rate $(45 \%)^{(23)}$. The average annual household income was R35 467 ( \$US 4430) in the year 2011. Approximately $30 \%$ of adults aged 20 years and above had an education level up to grade 12 and only $5 \%$ in the same age bracket had an educational level beyond grade $12^{(23)}$. The study site fits our definition of a 'resource-limited setting' as it has limited infrastructure (facilities and services) and lacks a highly skilled labour force such as health professional specialists. The majority of individuals from the setting have low literacy levels, low income and low material wealth.

\section{Study design and participants}

This was a 1-year randomised controlled study with two parallel groups. Study participants were men and women aged 40-70 years with T2DM and attending the two CHC. They were recruited face to face during their monthly clinic attendance while they were waiting to see a health professional. Recruitment was done over a period of 8 months from April 2010. A two-stage process was used to select the convenience sample. In the first stage, all consecutive patients who met the following criteria were selected: at least 1 year of living with diabetes; blood sugar levels of $10 \mathrm{mmol} / \mathrm{l}$ or above on two occasions in the previous 6 months; not on insulin therapy; regular attendance at the diabetic clinic; not pregnant or in full-time employment; and not planning to move from the study area during the study period. In the second stage the selected patients were screened for $\mathrm{HbA}_{1 \mathrm{c}}$ and only those with levels $\geq 8 \%$ were included in the final sample.

The study was conducted according to the guidelines laid down in the Declaration of Helsinki and all procedures involving human patients were approved by the Research Ethics Committee, Faculty of Health Sciences, University of Pretoria (protocol number 215/2009). Study participants gave written informed consent or verbal consent documented in the presence of a witness.

\section{Sample size}

For the primary outcome we needed to enrol at least forty participants per arm to detect a difference of $1 \%$ in $\mathrm{HbA}_{1 \mathrm{c}}$ (at 6 months) with $80 \%$ power at the $5 \%$ level of significance, assuming a standard deviation of $1.5 \%$ and allowing a $10 \%$ dropout rate. Since $\mathrm{HbA}_{1 \mathrm{c}}$ measurements are not routinely done at the $\mathrm{CHC}$, the standard deviation was based on our assessment of previous studies in our local context. We used the Stata ${ }^{\circledR}$ statistical software package version 11.1 to compute the sample size.

\section{Randomisation}

Participants were randomised to the intervention or control group with the use of random permuted blocks (block sizes of 2, 4 and 6) generated by a computer. Randomisation was done by participant irrespective of clinic. To allow equal chances for participants in both $\mathrm{CHC}$, we alternated the clinic visits during recruitment. Randomisation was stratified on the basis of sex and age (four strata). Sealed sequentially numbered opaque envelopes per each stratum were used. Upon confirmation of a participant's eligibility, the next envelope in sequence was opened and the treatment allocation entered on a randomisation list. Treatment allocation was done by the principal investigator.

\section{Blinding}

The health professionals serving the participants at the $\mathrm{CHC}$ and those involved in collection and analysis of blood specimens were masked to the treatment groups. The participants, the investigators and the fieldworker could not be blinded. 


\section{Intervention}

The control group participants received education materials (pamphlet and wall/fridge poster) and continued with the usual medical care at their respective $\mathrm{CHC}$. The intervention group received the same education materials and also participated in an NE programme. The NE programme consisted of three components: (i) the curriculum (eight weekly sessions, 2 to $2.5 \mathrm{~h}$ each; Table 1); (ii) follow-up sessions (four monthly meetings and two bi-monthly meetings each lasting $1.5 \mathrm{~h}$ ); and (iii) vegetable gardening (demonstration of sowing/transplantation of vegetables). The NE sessions were offered in five groups of six to ten participants. The groups were formed on the basis of recruitment time; therefore the NE sessions were staggered over the study period. The first group commenced in June 2010 and the last group completed in November 2011. Participants were restricted to their clinics as they receive their medication at a particular clinic and the NE sessions were offered at participants' respective $\mathrm{CHC}$. The total NE programme contact time was $26.5 \mathrm{~h}$ per group for the combined weekly and monthly meetings.

We (two dietitians included) developed the NE programme on the basis of previously assessed needs and preferences for $\mathrm{NE}$ in the target group ${ }^{(24)}$. Briefly, the needs assessment involved adults with T2DM and the health professionals serving them at the two CHC. Qualitative methods were used to generate information on the desirable characteristics of an NE programme for patients; their dietary practices; the barriers and facilitators to their dietary adherence; and their knowledge about diabetes

Table 1 Nutrition education programme curriculum

\begin{tabular}{|c|c|c|}
\hline Week & Topic & Content and activities \\
\hline 1 & What is diabetes mellitus? & $\begin{array}{l}\text { Nature of disease (explanation of what happens when one has diabetes, } \\
\text { including body's response to food in diabetic/non-diabetic states, insulin } \\
\text { action, causes/risk factors, types) } \\
\text { Symptoms and complications }\end{array}$ \\
\hline 2 & Treatment of diabetes & $\begin{array}{l}\text { Diet, exercise, medication and their roles in treatment } \\
\text { Aim for treatment and targets for good control } \\
\text { Causes, symptoms and management of hypoglycaemia and hyperglycaemia } \\
\text { Reflection on current practices and group discussion }\end{array}$ \\
\hline 3 & $\begin{array}{l}\text { Dietary guidelines: healthy eating, mixed } \\
\text { meals (balanced nutrition) }\end{array}$ & $\begin{array}{l}\text { Healthy eating: importance of regular and varied meals } \\
\text { Overview of food groups and their role in the body } \\
\text { Specific guidelines for starch, vegetables, fruits, and meats and alternatives } \\
\text { (additional information with respect to diabetes) } \\
\text { Guided discussion on improving dietary variety } \\
\text { Reflection on current dietary practices and group discussion }\end{array}$ \\
\hline 4 & $\begin{array}{l}\text { Improving vegetable supply through } \\
\text { gardening }\end{array}$ & $\begin{array}{l}\text { Discussion on barriers to vegetable and fruit intake and on how to improve } \\
\text { vegetable and fruit availability } \\
\text { Vegetable gardening demonstration: sowing and transplanting selected } \\
\text { vegetables* } \\
\text { Guided tour of the community health centre's previously established vegetable } \\
\text { gardens }\end{array}$ \\
\hline 5 & $\begin{array}{l}\text { Dietary guidelines continued: fats, salt, } \\
\text { sugar and water } \uparrow\end{array}$ & $\begin{array}{l}\text { Specific guidelines for each food group } \\
\text { Group activity: label reading of products on display } \\
\text { Reflection on current practices related to dietary guidelines and label reading } \\
\text { plus group discussion }\end{array}$ \\
\hline 6 & $\begin{array}{l}\text { Meal planning: portions and meal } \\
\text { frequency }\end{array}$ & $\begin{array}{l}\text { Facilitated group review of the effect of food on blood glucose } \\
\text { Discussion on importance of food portion control and regular meals } \\
\text { Guidelines for portion sizes } \\
\text { Demonstration: portion sizes (household measures, Zimbabwe hand jive, plate } \\
\text { model) } \\
\text { Group activity: practise portioning various commonly used foods } \\
\text { Reflection and group discussion about portion sizes and associated issues } \\
\text { such as hunger }\end{array}$ \\
\hline 7 & Meal planning: principles & $\begin{array}{l}\text { Planning meals on a limited budget, emphasis on variety and balance within } \\
\text { available resources } \\
\text { Group activity: } \\
\text { - costing of sample meals of foods commonly consumed in the community } \\
\text { - formulation of cheap mixed/balanced meals for foods commonly consumed in } \\
\text { the community } \\
\text { - group discussion and group goal setting }\end{array}$ \\
\hline 8 & $\begin{array}{l}\text { Meal preparation: healthy cooking with } \\
\text { diabetes } \\
\text { Hand outs: pamphlet and fridge/wall } \\
\text { poster }\end{array}$ & $\begin{array}{l}\text { Importance of legumes in general and in diabetes } \\
\text { Cooking demonstration and group cooking (one legume and one commonly } \\
\text { consumed vegetable) } \\
\text { Meal tasting and group discussion } \\
\text { Evaluation }\end{array}$ \\
\hline
\end{tabular}

*Achieved for one group only.

†Attendance of family members. 
and its treatment. The findings revealed diabetes knowledge deficits and inappropriate dietary practices (food portion control problems, inadequate intake of vegetables and fruits, unbalanced diets). Financial constraint was found to be the major barrier while social support was found to be the major facilitator to dietary adherence. Education at the clinic, group education, involvement of family and the provision of education materials were among the recommendations for the NE programme. We endeavoured to incorporate the suggestions for the NE as well as to address some of the identified problems/barriers to dietary adherence. For example, the vegetable gardening component was a strategy to improve access to vegetables through growing one's own vegetables with the aim of improving participants' vegetable consumption. The NE was developed on the underpinnings of wellestablished health behaviour models, namely the Social Cognitive Theory ${ }^{(25)}$, the Health Belief Model ${ }^{(26)}$ and the Knowledge Attitude Behaviour ${ }^{(26)}$ model. Figure 1 details the selected constructs of the behaviour models and their application in the study as well as the NE programme components.

The overall goal of the NE programme was to improve glycaemic control $\left(\mathrm{HbA}_{1 \mathrm{c}}\right)$ and other clinical outcomes (BMI, blood lipids, blood pressure) through improved dietary behaviours (dietary intake including portions of starchy foods) and behaviour-mediating factors (knowledge, beliefs and attitudes, self-efficacy and goal setting).
The behaviour-mediating factors (knowledge and attitudes) are reported elsewhere (JW Muchiri, GJ Gericke and P Rheeder, unpublished results), while the rest (selfefficacy and goal setting) were not measured. Although all aspects of diet for people with diabetes were addressed, the main behaviours focused on were reducing intake of starchy foods (aiming at 6-11 servings/d), increasing the consumption of vegetables and fruits ( $4-5$ servings/d) and improving meal balance as reflected by intakes of macronutrients within the acceptable macronutrient distribution range (AMDR); i.e. carbohydrate $45-65 \%$, protein $10-35 \%$ and fat $20-35 \%^{(27)}$.

The NE programme curriculum covered content on diabetes pathophysiology, risk factors, symptoms, complications, treatment goals and modalities, and dietary principles, which included food groups and meal balance, portion control and planning meals on a limited budget (Table 1). The Zakhe diabetes education flip chart (adapted with modification) ${ }^{(28)}$ and the South African food-based dietary guidelines flip chart ${ }^{(29)}$ were used to teach the content on diabetes and the dietary guidelines, respectively. The facilitation of the programme was done as follows: the sub-district dietitian (25\% of weekly sessions); a final-year nutrition and food science university student from the study site (65\% of weekly and $90 \%$ of follow-up sessions); the principal investigator, an experienced dietitian (10\% of weekly and follow-up sessions); and the sub-district horticulture officer (vegetable

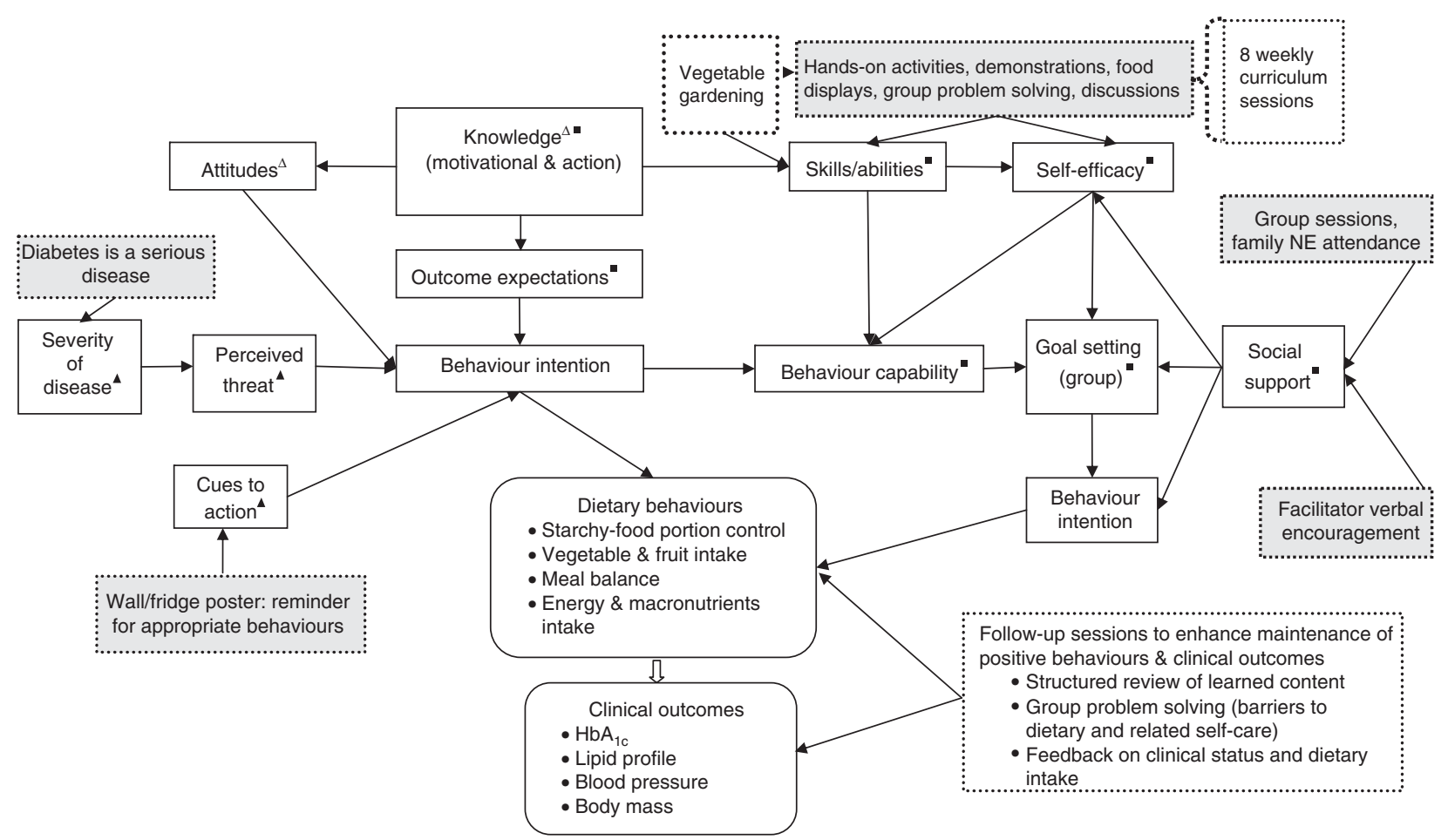

Fig. 1 Nutrition education (NE) programme components (\%:) and selected constructs of the behaviour models ( $\Delta$, Knowledge Attitude Behaviour model; $\boldsymbol{\Delta}$. Health Belief Model; $\mathbf{0}$, Social Cognitive Theory) and their application in the study (:-i:) 
gardening demonstration). The local language was used in the majority of the sessions (90\%). The rest were offered in English by the principal investigator with local language translations carried out. The sub-district dietitian and the student (appointed fieldworker) had been trained by the principal investigator to deliver the sessions and a training manual was used during the sessions.

To prevent/minimise contamination between the intervention and control groups, patients were asked not to share information with other patients ${ }^{(30)}$. Outcome assessments were carried out on different days for each of the groups and the NE sessions were conducted in different $\mathrm{CHC}$ blocks from where patient consultations were done.

\section{Outcomes}

The primary outcome was the change in $\mathrm{HbA}_{1 \mathrm{c}}$ at 6 months. The secondary outcomes were changes in other clinical outcomes (BMI, blood pressure and blood lipids), $\mathrm{HbA}_{1 \mathrm{c}}$ and dietary behaviours at 12 months.

\section{Hypothesis}

We hypothesised that an NE programme customised to the expressed needs and preferences for NE would induce significant improvements in the investigated outcomes in the intervention group at 6 months and that these improvements would be sustained at 12 months.

\section{Clinical outcomes}

Non-fasting venous blood samples were analysed for $\mathrm{HbA}_{1 \mathrm{c}}$ and full lipid profile (total cholesterol, LDLcholesterol, HDL-cholesterol and TAG) at the Steve Biko Academic Hospital Core laboratory of the National Health Laboratory Services (Pretoria). SYNCHRON LX ${ }^{\circledR}$ in conjunction with Unicel ${ }^{\circledR}$ DxC 600/800 system(s) (Beckman Coulter, Fullerton, CA, USA) were used for the analysis. The $\mathrm{HbA}_{1 \mathrm{c}}$ results are traceable to those of the International Federation of Clinical Chemistry (IFCC) calibrators.

Weight and height were measured using standard techniques with participants barefooted and in light clothing $^{(31)}$. Weight was determined to the nearest $0 \cdot 1 \mathrm{~kg}$ using a calibrated electronic scale (Seca 208). Height was measured to the nearest $0 \cdot 1 \mathrm{~cm}$ using a portable stadiometer (Seca 214). Two measurements each of the weight and height were taken and the average of each used for calculations. BMI $\left(\mathrm{kg} / \mathrm{m}^{2}\right)$ was calculated by dividing the participant's average body weight by the square of his/her average height. Blood pressure was measured according to standard guidelines ${ }^{(32)}$ using a digital pressure monitor (Omron 705CP). Two measurements were taken and in cases where there was a difference of more than $5 \mathrm{mmHg}$ between the readings, one or two more measurements were taken. The mean of the two closest measurements was used to determine mean blood pressure.

Data on medication prescribed for the treatment of diabetes were collected at baseline and reviewed during each of the post-intervention outcome assessments. A medication increase was defined as an increase in the dose or number of oral glucose-lowering agents. A medication decrease was defined as a reduction in the number or quantity of the oral agents.

\section{Dietary outcomes}

Three face-to-face $24 \mathrm{~h}$ dietary recalls (two weekdays and one weekend day) on non-consecutive days assessed dietary intake. Bean bag mounds ${ }^{(33)}$ fruit models and standardised commonly used household measures (cups, glasses, spoons, bowls, spoons, etc.) were used to assist participants in estimating consumed food/fluids portions. The South Africa Medical Research Council FoodFinder $3^{\circledR}$ diet analysis software was used to analyse the $24 \mathrm{~h}$ diet recalls. Data on growing one's own vegetables (yes/no) and how the participants used the vegetables were also collected.

\section{Statistical analysis}

Stata ${ }^{\circledR}$ version $12 \cdot 1$ was used for all statistical analyses. We analysed the data according to an intention-to-treat analysis using the last observation carried forward ${ }^{(34)}$. We used ANCOVA to compare the intervention group and control group on the measured outcomes postintervention, using the baseline values, age, sex and clinic as covariates. Rank ANCOVA ${ }^{(35)}$ was used for dietary intake as the majority of the data were skewed. TAG values were normalised through logarithmic transformation ${ }^{(36)}$. The level of significance for all tests was set at $\alpha<0.05$ for a two-tailed test.

\section{Results}

\section{Participants}

Figure 2 shows the flow of participants through the study. Out of eighty-two (eleven males) participants who were randomised, seventy-six ( $92.7 \%$; eleven males) completed the study. The mean age of participants at baseline was 58.8 (sD 7.7) years. Table 2 shows the participants' sociodemographic characteristics and diabetes medication use for the intervention and control groups at baseline. All participants were black Africans. The majority in both groups were unemployed ( $>80 \%$ ) with a high proportion depending on a pension $(>45 \%)$ or on other forms of grants $(>14 \%)$ for their livelihood. More participants in each group, $43.9 \%$ and $39.0 \%$ for the intervention group and control group, respectively, had 7-9 years of schooling. All participants were on oral hypoglycaemic agents, with the majority in both groups ( $>70 \%$ ) being on a combination of biguanides and sulfonylureas.

\section{Programme session attendance}

Thirty-three (80.5\%) intervention-group participants attended six or more sessions of the eight weekly 


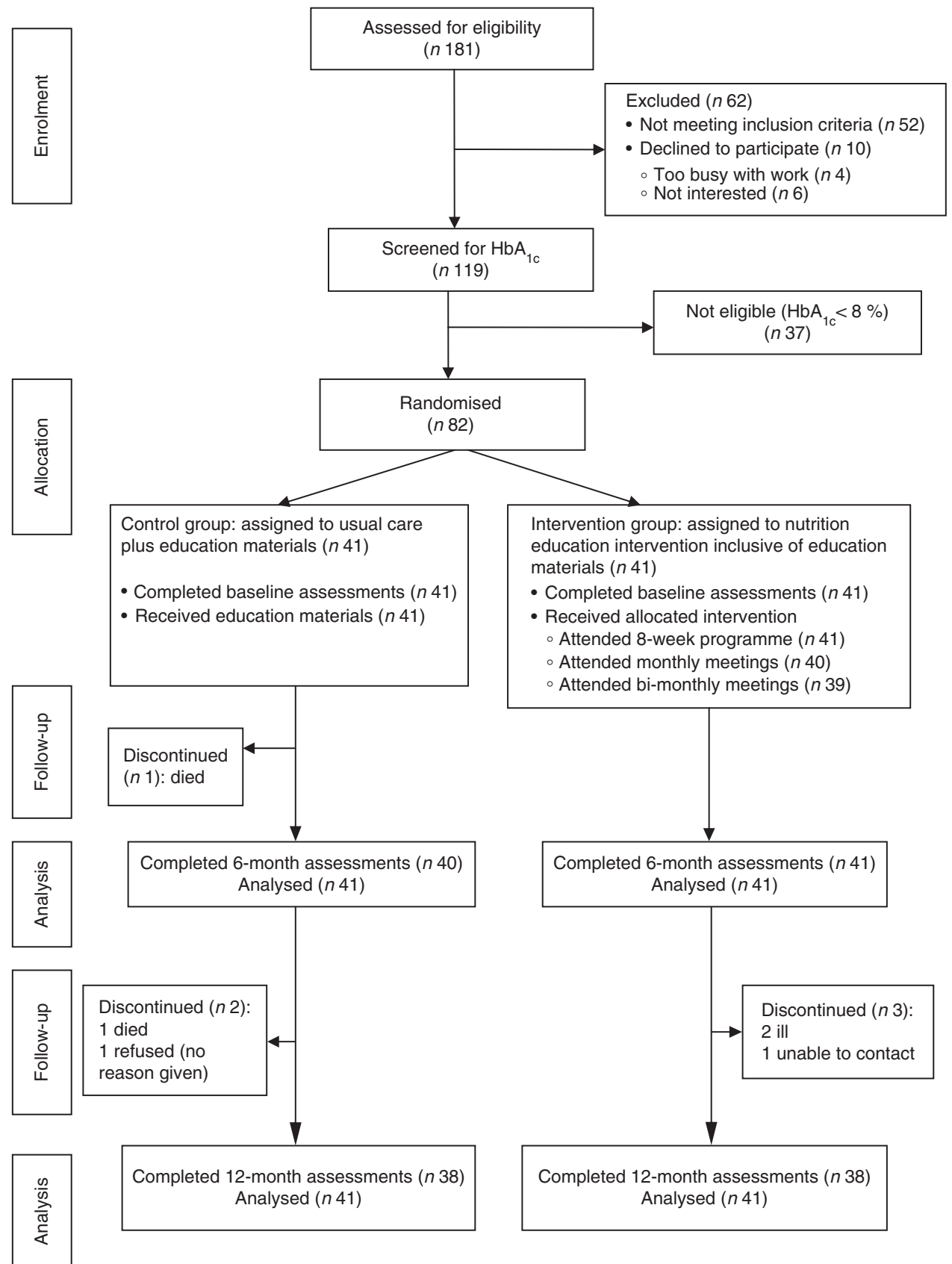

Fig. 2 Flow of participants through the study

meetings, of whom sixteen (39.0\%) attended all the meetings. The average attendance at monthly and bimonthly follow-up meetings was more than $80 \%$.

\section{Diabetes medication changes}

At 6 months, three $(7 \cdot 3 \%)$ intervention-group participants decreased their diabetes medication while one $(2.5 \%)$ control-group participant increased his medication $(P=0.26)$. At 12 months, three (7.9\%) $v$. seven (18.4\%) intervention- and control-group participants, respectively, increased their diabetes medication. One $(2 \cdot 6 \%)$ controlgroup participant decreased her medication $(P=0 \cdot 11)$.

\section{Clinical outcomes}

Table 3 shows the mean baseline data and the baseline-, age-, sex- and clinic-adjusted 6- and 12-month clinical outcomes. There were no significant group differences in the clinical variables at baseline. Post-intervention, mean difference between the intervention and control groups for $\mathrm{HbA}_{1 \mathrm{c}}$ was $-0.64 \%(95 \% \mathrm{CI}-0.19,1.50 \% ; P=0.13)$ at 6 months and $-0.63 \%$ (95\% CI $0.26,1.50 \% ; P=0.16)$ at 12 months. Few participants achieved the targets for $\mathrm{HbA}_{1 \mathrm{c}}(<7 \%)$ : four (9.8\%) $v$. one $(2.4 \% ; P=0.20)$ at 6 months and five $(12.2 \%)$ $v$. one $(2 \cdot 4 \% ; P=0.20)$ at 12 months for the intervention and control groups, respectively (data not shown). 
Table 2 Demographic characteristics and diabetes medication at baseline: comparisons between the intervention and control groups of adults aged 40-70 years with type 2 diabetes mellitus, Moretele sub-district (North West Province), South Africa, April 2010-November 2011

\begin{tabular}{|c|c|c|c|c|}
\hline \multirow[b]{2}{*}{ Characteristic } & \multicolumn{2}{|c|}{ Intervention group ( $n$ 41) } & \multicolumn{2}{|c|}{ Control group ( $n 41)$} \\
\hline & Mean, median or $n$ & SD, IQR or \% & Mean, median or $n$ & SD, IQR or $\%$ \\
\hline Age (years)* & $59 \cdot 4$ & 6.9 & $58 \cdot 2$ & 8.0 \\
\hline \multirow{2}{*}{\multicolumn{5}{|c|}{ Ethnicity }} \\
\hline & & & & \\
\hline Black Africans & 41 & $100 \cdot 0$ & 41 & $100 \cdot 0$ \\
\hline \multicolumn{5}{|l|}{ Sex $\ddagger$} \\
\hline Male & 5 & $12 \cdot 2$ & 6 & 14.6 \\
\hline Female & 36 & $87 \cdot 8$ & 35 & 85.4 \\
\hline \multicolumn{5}{|l|}{ Age-sex $\ddagger$} \\
\hline Males $40-60$ years & 2 & 4.9 & 3 & $7 \cdot 3$ \\
\hline Males $61-70$ years & 3 & $7 \cdot 3$ & 3 & $7 \cdot 3$ \\
\hline Females $40-60$ years & 20 & $48 \cdot 8$ & 19 & $46 \cdot 4$ \\
\hline Females $61-70$ years & 16 & 39.0 & 16 & $39 \cdot 0$ \\
\hline \multicolumn{5}{|l|}{ Marital status $\ddagger$} \\
\hline Single & 6 & $14 \cdot 6$ & 6 & 14.6 \\
\hline Married & 25 & $61 \cdot 1$ & 28 & $68 \cdot 3$ \\
\hline Widowed & 6 & 14.6 & 6 & 14.6 \\
\hline Separated/divorced & 4 & 9.8 & 1 & 2.5 \\
\hline \multicolumn{5}{|l|}{ Living situation $\ddagger$} \\
\hline Live with family & 37 & $90 \cdot 2$ & 39 & $95 \cdot 1$ \\
\hline Live alone & 3 & $7 \cdot 3$ & 2 & 4.9 \\
\hline Other & 1 & 2.5 & 0 & 0.0 \\
\hline \multicolumn{5}{|l|}{ Education level $\ddagger$} \\
\hline No formal education & 2 & 4.9 & 5 & $12 \cdot 2$ \\
\hline Grade $1-6$ & $1 \overline{1}$ & $26 \cdot 8$ & 11 & $26 \cdot 8$ \\
\hline Grade 7-9 & 18 & 43.9 & 16 & 39.0 \\
\hline Grade $10-12$ & 7 & $17 \cdot 1$ & 8 & $19 \cdot 5$ \\
\hline Post grade 12 & 3 & $7 \cdot 3$ & 1 & 2.5 \\
\hline \multicolumn{5}{|l|}{ Employment status $\ddagger$} \\
\hline Employed & 2 & 4.9 & 6 & 14.6 \\
\hline Not employed & 39 & $95 \cdot 1$ & 35 & 84.4 \\
\hline \multicolumn{5}{|l|}{ Oral hypoglycaemicsł } \\
\hline Biguanides & 8 & 19.5 & 7 & $17 \cdot 1$ \\
\hline Sulfoynlureas + biguanides & 29 & $70 \cdot 7$ & 29 & $70 \cdot 7$ \\
\hline Sulfonylureas & 4 & 9.8 & 5 & $12 \cdot 2$ \\
\hline
\end{tabular}

*Data presented are mean and standard deviation.

†Data presented are median and interquartile range (IQR).

‡Data presented are number and percentage.

There were no significant between-group differences for mean BMI, mean total cholesterol, mean LDL-cholesterol, mean HDL-cholesterol and mean TAG at 6 and 12 months, although the parameters tended to be higher in the control group. Systolic and diastolic blood pressures were not significantly different between the groups at 6 months and 12 months, but tended to be lower in the control group at 6 months. Adjustment showed high baseline values to influence all clinical outcomes $(P<0 \cdot 001)$ at both 6 and 12 months, $\mathrm{HbA}_{1 \mathrm{c}}$ at 6 months to be influenced by age $-0.06 \%(P=0.032)$ and female sex $+1.56 \%(P=0.013)$, and clinic to influence BMI at 12 months $-0.82 \mathrm{~kg} / \mathrm{m}^{2}$ $(P=0 \cdot 027$; clinic 2$)$.

With regard to the effects of non-adjustment and minimum adjustment (baseline only) models on clinical outcomes (data not shown), only $\mathrm{HbA}_{1 \mathrm{c}}$ was significantly higher in the control group for the non-adjusted model at both 6 months, $+1 \cdot 11 \%$ (95\% CI $0 \cdot 05,2 \cdot 10 \%$; $P=0.04)$, and 12 months, $+1.03 \%$ (95\% CI $0.01,2 \cdot 60 \% ; P=0.048)$.
With the minimum adjustment model, only TAG was significantly higher in the control group $(P=0.001)$ and $(P=0.024)$ at 6 and 12 months, respectively.

\section{Dietary outcomes}

Table 4 presents the baseline data, 6-month and 12-month dietary outcomes (values are unadjusted medians; $P$ value is for outcome adjusted for baseline, age, sex and clinic). The dietary variables were similar at baseline, apart from the median percentage of energy from total fat and polyunsaturated fat, which were significantly higher in the control group. Post-intervention, both the intervention and control groups reduced their intake of starchy foods (number of servings). The intervention group had a greater reduction and significantly lower median intake compared with the control group at 6 months $(9 \cdot 3 v \cdot 10 \cdot 8$ servings/d, $P=0.003)$ and at 12 months $(9.7 v .11 \cdot 8$ servings $/ \mathrm{d}, P=0 \cdot 01)$. The intervention group had a significantly lower median energy intake at 12 months $(5988 v .6946 \mathrm{~kJ} / \mathrm{d}, P=0 \cdot 017)$ 


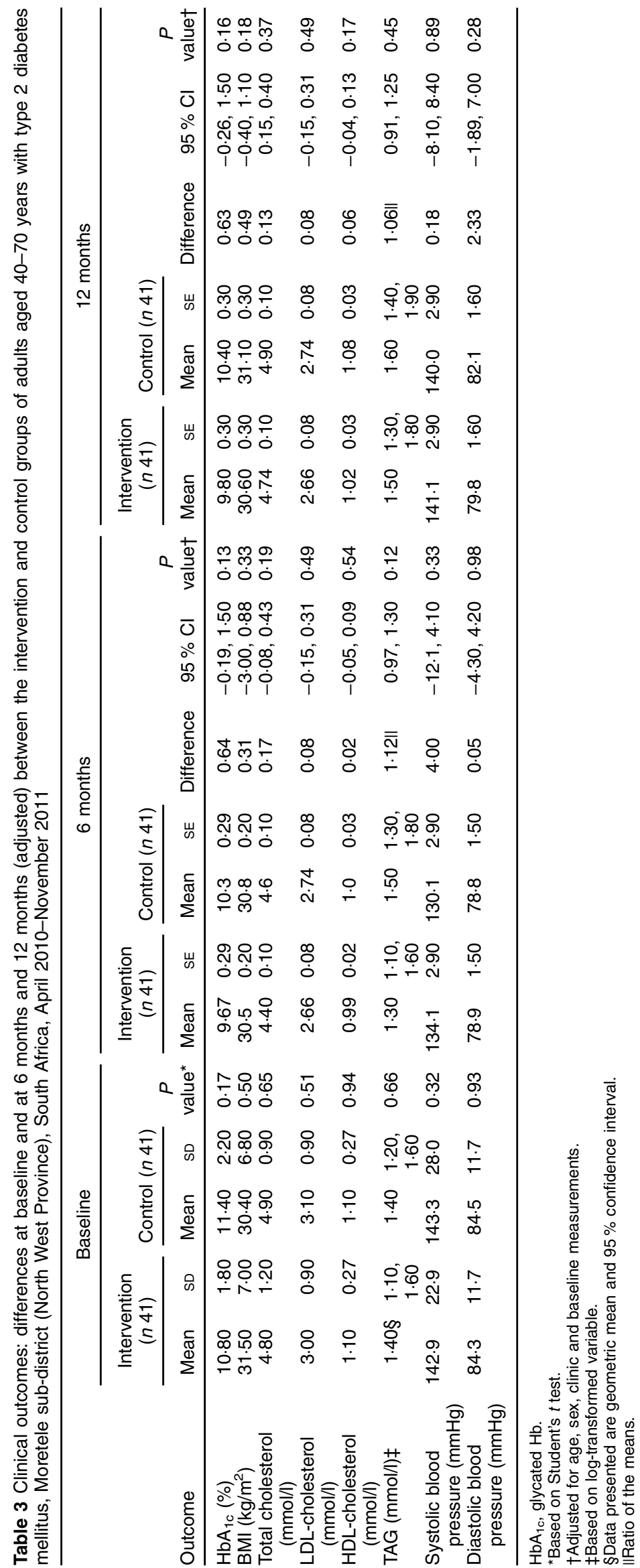




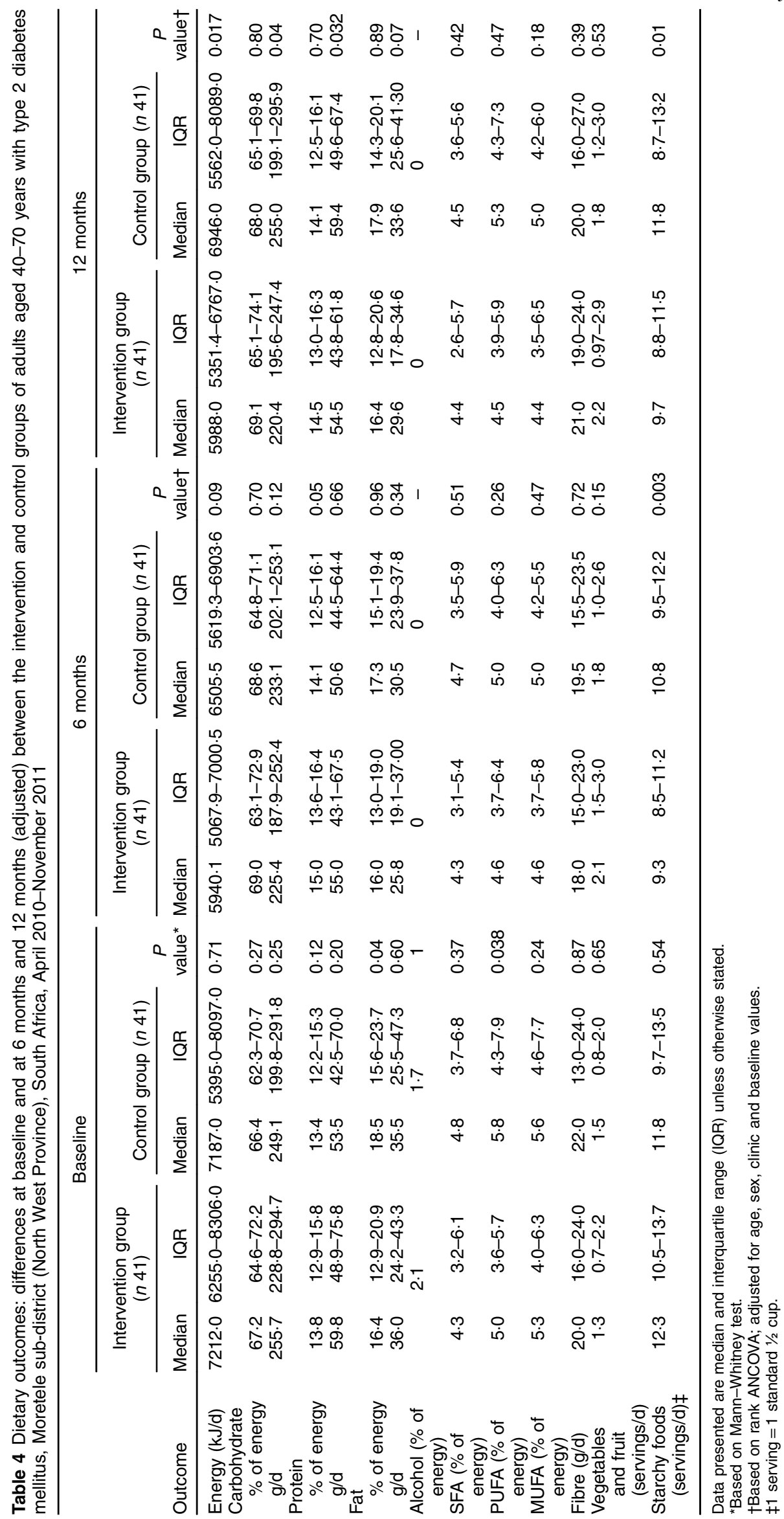


compared with the control group. There were no significant group differences in the intake of energy from macronutrients and all fatty acids at 6 and 12 months. However, the intervention group had a higher and close to significant intake of energy from protein at 6 months. Absolute macronutrient intakes $(\mathrm{g} / \mathrm{d})$ were significantly lower for carbohydrate in the intervention group at 12 months $(P=0.04)$ and significantly higher for protein for the control group at 12 months $(P=0.032)$. There were no significant group differences in the intakes of vegetables and fruits and fibre at 6 and 12 months.

With respect to effects of minimum adjustment (baseline only) and non-adjustment (data not shown), the nonadjusted model showed significant results for only intakes of starchy foods $(P=0.031)$ and protein $(P=0.021)$ at 6 months. The baseline-adjusted model showed significant effects for protein $(P=0.045)$ at 6 months and starchy foods at both 6 months $(P=0.003)$ and 12 months $(P=0.009)$.

\section{Discussion}

In the present study we hypothesised that an NE programme customised to the expressed needs and preferences for NE would lead to significantly better outcomes in the intervention group at 6 months and that the improved outcomes would be sustained at 12 months. The results do not support this hypothesis for $\mathrm{HbA}_{1 \mathrm{c}}$ and the other clinical outcomes. $\mathrm{HbA}_{1 \mathrm{c}}$ levels were lower in the intervention group but not significantly lower than in the control group. Non-significant changes in $\mathrm{HbA}_{1 \mathrm{c}}$ results have been reported in other dietary interventions offered in group format ${ }^{(37,38)}$. Other group-based interventions, notably those offered by registered dietitians $(\mathrm{RD})^{(39-41)}$ or with a dietitian as a member of a multidisciplinary team, have reported significant improvements in $\mathrm{HbA}_{1 \mathrm{c}}{ }^{(42)}$. In our study, the majority of the sessions were facilitated by a final-year university student not fully qualified in the field of nutrition or dietetics. The reason for using this person was that the sub-district dietitian was not fully available because of other work demands. The investigators were not conversant with the local language and the NE was planned to be culturally appropriate. The facilitation of the NE by the student, and not an RD, might have impacted on its delivery, even though every effort was made to ensure delivery as intended. Given the complexity of nutrition issues and behaviour change ${ }^{(43)}$, it could be that the role of a dietitian, the professional considered most suitable to provide diabetes nutrition therapy ${ }^{(44)}$, would be crucial in this study population, who indicated they had not previously participated in any diabetes-specific education. NE offered by an RD or where the RD is part of a team has been shown to significantly improve glycaemic control ${ }^{(45)}$. There are limited data on studies that have used students in dietary interventions for people with diabetes. In one study where nutrition students (master's level) were used, significant improvement in $\mathrm{HbA}_{1 \mathrm{c}}$ was observed ${ }^{(46)}$.

Factors that may have contributed to the improvements in $\mathrm{HbA}_{1 \mathrm{C}}$ in the control group and hence diluted the $\mathrm{NE}$ effects on $\mathrm{HbA}_{1 \mathrm{c}}$ include: the two-stage recruitment process that made participants aware that inclusion in the final sample would be based on higher values of $\mathrm{HbA}_{1 \mathrm{c}}$ (after screening); the participants' awareness that they were being studied (the so-called 'Hawthorn effect'); and the feedback given on their laboratory results (since the participants wanted this information). These factors could have motivated them to make behaviour changes. In addition, an increase in glucose-lowering medication (dosage and number), although non-significant, was higher in the control group.

Overall, the $\mathrm{NE}$ reduced $\mathrm{HbA}_{1 \mathrm{c}}$ levels by $0.64 \%$ at 6 months and $0.63 \%$ at 12 months. This reduction is comparable with Deakin et al.'s study that reported a significant reduction of $0.6 \%$ at 14 months in the intervention group ${ }^{(40)}$. The magnitude of reduction is higher than that reported by Coppell et al. of $0.4 \%$ in a study that achieved significant group differences in patients on optimal drug treatment ${ }^{(47)}$. The reduction is also higher than the net reduction of $0.26 \%(95 \% \mathrm{CI}-0.05,-0.48 \%)$ expected for DSME of duration of four or more months in the meta-analysis by Norris et al. $^{(48)}$. The reduction in $\mathrm{HbA}_{1 \mathrm{c}}$ levels in our study was, however, lower than that reported for MNT ( $0.9 \%)$ offered by RD in individuals with T2DM with an average duration of 4 years ${ }^{(49)}$. Although the reduction in $\mathrm{HbA}_{1 \mathrm{c}}$ was not statistically significant, it may be of clinical importance in reducing the risk of diabetes-related complications. According to the United Kingdom Prospective Diabetes Study (UKPDS) ${ }^{(50)}$, a $1 \%$ decrease in $\mathrm{HbA}_{1 \mathrm{c}}$ resulted in a reduction of $37 \%$ for microvascular complications and $21 \%$ for deaths related to diabetes. If risk reduction is proportional to $\mathrm{HbA}_{1 \mathrm{c}}$ reduction, then based on the UKPDS, the present study would reduce the risk for microvascular complications by $25 \%$ and deaths by $14 \%$. In addition, a reduction of at least $0.5 \%$ in $\mathrm{HbA}_{1 \mathrm{c}}$ in 6 months is considered a beneficial metabolic response ${ }^{(51)}$.

The limited improvements in BMI have been reported in some other studies ${ }^{(40,52)}$, further confirming the problem with losing weight in people with T2DM as reported in the meta-analysis by Norris et $a l .{ }^{(53)}$. A positive finding in our study was that lower than the baseline levels of BMI were achieved in the intervention group at the end of the study while in the control group they tended to increase. The lack of significant improvement in BMI despite a reduction in energy intake could in part be due to under-reporting of food intake that is common with obese T2DM individuals $^{(54)}$ and those of low socio-economic status ${ }^{(55)}$ and/or improvements in glycaemia accompanied with the resolution in glycosuria $^{(56)}$ as participants had poorly controlled diabetes. 
Non-significant improvements in the full lipid profile have been reported in other studies ${ }^{(41,52)}$, even in lowincome and underserved settings ${ }^{(38,57)}$ and studies involving diet and physical activity with weight loss as the primary outcome ${ }^{(42,58)}$. Despite the non-significant improvements in the lipid profile our study showed some positive effects. First, the mean total cholesterol and TAG levels were within the recommendations of the Society of Endocrinology, Metabolism and Diabetes of South Africa of $<4.5 \mathrm{mmol} / 1$ and $<1.5 \mathrm{mmol} / 1$, respectively $^{(59)}$, at 6 months for the intervention group. Second, total cholesterol, LDL-cholesterol and TAG tended to be lower in the intervention group at the two time periods - a finding also observed by Anderson-Lofting et al. ${ }^{(38)}$. The non-significant improvements in blood pressure may be explained by the limited improvements in BMI.

The NE programme significantly reduced the intake of energy at 12 months and servings of starchy foods at 6 and 12 months. The significant reduction of starchy-food intake in the intervention group is likely to have occurred for the following reasons. First, the importance of controlling the amounts of food consumed, especially starchy foods, was emphasised. Second, guidelines for portioning various food groups in a meal were provided, with the use of simple visual approaches, namely the plate model $^{(60)}$ and the Zimbabwe hand jive ${ }^{(61)}$. In addition flip charts, demonstrations and displays of sample meals using culturally appropriate foods were used. Finally, participants had a chance to practise the portioning of foods with the use of the guidelines. No published studies assessing starchy-food intake (servings) in people with diabetes were found.

The levels of energy decline in the intervention group are comparable to those reported by Huang et al. ${ }^{(52)}$. The greater decline in the intervention group appears to have been affected by the greater reduction in starchy-food intake (servings), as the percentage of energy from fats and protein changed only slightly during the study. The reasons for the non-significant changes in the percentage of energy from fat and fatty acids could be a result of the fact that even at baseline the intakes were far below the recommendations, implying that it would be more difficult to reduce the levels.

Percentage intake of energy from carbohydrate at baseline and post-intervention in both groups was above the guideline of $45-65 \%{ }^{(62)}$ used in the present study (not prescribed). The levels ( $>65 \%$ ) would be classified as 'high carbohydrate' according to Wheeler et al. ${ }^{(63)}$. Wheeler et al.'s ${ }^{(63)}$ review indicated a non-unanimous agreement on the percentage of energy from carbohydrates shown to confer optimal glycaemic control due to conflict in results for various levels of carbohydrate in the reviewed studies. Therefore, it cannot be concluded that the high carbohydrate intake in our study contributed to the non-significant changes in glycaemic control. The high carbohydrate intake among people with T2DM seems to be typical in black communities in resource-limited settings in South Africa ${ }^{(14)}$. This observation could be explained by the fact that carbohydrate-rich foods are often cheaper ${ }^{(64)}$.

Post-intervention fibre intakes were close to the baseline levels and they did not meet the study guidelines $(25 \mathrm{~g} / \mathrm{d})$. The intakes were similar to those reported in people with T2DM in South Africa ${ }^{(14)}$. The non-significant results in vegetable and fruit intake are in agreement with findings from a study by Yannakoulia et $a l .^{(37)}$. The limited improvement in vegetable and fruit intake in our study, despite the reported increase in the number of intervention participants growing their own vegetables (17/41 v. $5 / 41, P=0.003$, at 6 and 12 months) and mainly using them for home consumption (data not shown), is an unexpected result that warrants further investigation.

In regard to the goal of enhancing meal balance based on the AMDR, there were no significant group differences from baseline to post-intervention. Carbohydrate intakes were higher than the AMDR throughout the study for both groups, despite the decrease in absolute amounts. The proportion of energy contributed by protein was within the AMDR and improved slightly through the study although the absolute amounts generally decreased. Fat contribution to energy was much lower than the AMDR. While under-reporting of dietary intake cannot be ruled out $^{(54)}$, the pattern of macronutrient contributions to energy in the present study is similar to that observed in the South African study ${ }^{(14)}$.

The following factors could likely have contributed to the non-significant improvements in vegetable and fruit intake and meal balance. A lack of participation in personal goal setting by the intervention group members was observed. This problem could be related to the low literacy levels of the study participants. The absence of personalised goal setting might have interfered with the commitment to attaining the group goals. The participants may also not have improved their self-efficacy for these two dietary behaviours. Self-efficacy was not, however, measured in the study. Goal setting ${ }^{(65)}$ and self-efficacy ${ }^{(66)}$ have been shown to facilitate dietary and related behaviour changes and even to influence glycaemic control in individuals with diabetes ${ }^{(67)}$.

Several aspects of the present study contributed to its strength. These include the randomised study design, the low attrition rates and the monitoring of the changes in glucose-lowering medication. The 12-month study period was long enough to observe changes in the measured outcomes and their subsequent stability beyond 6 months. Other strengths included the tailoring of the NE to participants' expressed needs and preferences. The use of facilitators from the study setting in the majority of the sessions was an additional strength as they had the same cultural orientation as the participants. The study also had limitations. The study power was lower than initially planned as a result of a higher standard deviation than 
anticipated ( $\mathrm{SD}=2.0$ instead of 1.5$)$, implying that a minimum of 126 participants were needed. Challenges with recruitment, however, made it difficult to obtain additional participants. The initial aim of achieving a $1 \%$ (we based this value on previous MNT studies) difference in $\mathrm{HbA}_{1 \mathrm{c}}$ was also probably over-optimistic and, with hindsight, the sample size should have been planned on a minimal clinical significant difference of $0.5 \%$. Sample size for the secondary outcomes was not calculated nor adjustment for the type 1 error rate done. This makes it uncertain as to whether the study was adequately powered for the secondary outcomes and hence the results on these outcomes should be viewed with this issue in mind. However, we regarded these analyses exploratory to investigate, for example, by which possible means the intervention could determine change in the primary outcome. Whereas measures were taken to prevent contamination between the participants in the intervention and control groups, such an occurrence cannot be ruled out. Information sharing between participants could have occurred during their monthly $\mathrm{CHC}$ attendance. However, the effect, if any, would likely not be significant. According to expert consensus, interventions focusing on behaviour are less vulnerable to contamination compared with knowledge focused ones ${ }^{(68)}$, and in our study knowledge scores were significantly higher in the intervention group (JW Muchiri, GJ Gericke and P Rheeder, unpublished results). In addition, given the scope (intensity and duration) of the NE programme the 'dose' exposure on the controlgroup participants would be low, as the whole NE package was unlikely to be transferred ${ }^{(30)}$.

The use of non-fasting blood samples could have influenced the accuracy of the evaluated lipids - particularly TAG, which remain elevated for several hours postprandial ${ }^{(69)}$. However, asking participants to fast before assessments was seen as a factor that could lead to non-compliance in some participants or discourage participation. The greater number of women compared with men could limit the generalisation of the results. This scenario seems to be typical of the study population as previously observed ${ }^{(24)}$. The occurrence is likely due to the relatively small number of males observed to attend the CHC. It could also be associated with the lower diabetes prevalence rates in males in comparison with females reported in South Africa ${ }^{(3)}$. The facilitation of most of the NE by a student rather than an experienced dietitian could be viewed as a limitation. The non-optimal application of goal setting and self-efficacy constructs of the Social Cognitive Theory was also a limitation in the study.

\section{Conclusions}

We conclude that the NE programme did not significantly improve glycaemic control or other clinical outcomes. However, a positive trend was observed in that $\mathrm{HbA}_{1 \mathrm{c}}$, BMI, total cholesterol and LDL-cholesterol decreased more in the intervention group.
The NE programme significantly improved two dietary outcomes: reduction in the intakes of starchy foods (servings) and energy. However, it did not achieve the objective of improving vegetable and fruit intake and enhancing meal balance in the study population.

The findings from the study demonstrate that an NE programme that is customised to the participants' needs and preferences for NE can improve specific dietary behaviours and has the potential for improving $\mathrm{HbA}_{1 \mathrm{c}}$ and other clinical outcomes. Nevertheless, delivering such a programme as part of routine practice in the study setting would be a challenge due to inadequate personnel and infrastructure. Future studies should explore the use of other trained personnel such as community health workers if structured NE is to be offered routinely in resource-limited settings. In addition, in order to maximise the benefits from NE interventions for people with T2DM in resource-limited settings, such studies should optimally apply individualised goal setting and self-efficacy skills training and the assessment thereof.

\section{Acknowledgements}

Acknowledgements: The authors thank Barbara English for her assistance with language editing. Kemmone Mashishi, Keabestwe Kodi and Ronald Thobejane are also thanked for facilitating the nutrition education sessions. The support of the staff from the two community health centres and the cooperation of the patients involved in the study are greatly appreciated. Financial support: This study was supported by research grants from the South African Sugar Association (grant number 212) and Nestlé Nutrition Institute Africa. These organisations had no role in the design, analysis or writing of the article. Conflict of interest: None. Authorship: All authors contributed to the conception and design of the study. P.R. and G.J.G. supervised the study. G.J.G. provided theoretical expertise on the NE curriculum and critically revised the first draft of the manuscript. J.W.M. was involved in the implementation of the intervention and data collection, performed statistical analysis and drafted the manuscript. P.R. computed the sample size, provided the statistical expertise and contributed to the analysis. All authors contributed to the interpretation of the results. All authors read and approved the final manuscript. Ethics of buman subject participation: The study was approved by the Research Ethics Committee, Faculty of Health Sciences, University of Pretoria (protocol number 215/2009).

\section{References}

1. Shaw JE, Sicree RA \& Zimmet PZ (2010) Global estimates of the prevalence of diabetes for 2010 and 2030. Diabetes Res Clin Pract 87, 4-14.

2. Whiting DR, Guariguata L, Weil C et al. (2011) IDF Diabetes Atlas: global estimates of the prevalence of diabetes for 2011 and 2030. Diabetes Res Clin Pract 94, 311-321. 
3. Bradshaw D, Norman R, Pieterse D et al. (2007) Estimating the burden of disease attributable to diabetes in South Africa in 2000. S Afr Med J 97, 700-706.

4. International Diabetes Federation (2011) IDF Diabetes Atlas, 5th ed. Brussels: IDF; available at http://www.idf.org/ diabetesatlas

5. Alberts M, Urdal P, Steyn K et al. (2005) Prevalence of cardiovascular diseases and associated risk factors in a rural black population of South Africa. Eur J Cardiovasc Prev Rehab 12, 347-354.

6. Roper NA, Bilous RW, Kelly WF et al. (2001) Excess mortality in a population with diabetes and the impact of material deprivation: longitudinal, population based study. BMJ 322, 1389-1393.

7. Bell RA, Camacho F, Goonan K et al. (2001) Quality of diabetes care among low-income patients in North Carolina. Am J Prev Med 21, 124-131.

8. Rotchford A \& Rotchford K (2002) Diabetes in rural South Africa - an assessment of care and complications. S Afr Med J 92, 536-541.

9. Eakin EG, Bull SS, Glasgow RE et al. (2002) Reaching those most in need: a review of diabetes self-management interventions in disadvantaged populations. Diabetes Metab Res Rev 18, 26-35.

10. Cox RH, Carpenter JP, Bruce FA et al. (2004) Characteristics of low-income African-American and Caucasian adults that are important in self-management of type 2 diabetes. J Community Health 29, 155-170.

11. Glasgow RE, Hampson SE, Strycker LA et al. (1997) Personal-model beliefs and social-environmental barriers related to diabetes self-management. Diabetes Care 20, 556-561.

12. Yannakoulia M (2006) Eating behavior among type 2 diabetic patients: a poorly recognized aspect in a poorly controlled disease. Rev Diabet Stud 3, 11-16.

13. Frandsen KB \& Kristensen JS (2002) Diet and lifestyle in type 2 diabetes: the patient's perspective. Pract Diabetes Int 19, 77-80.

14. Nthangeni G, Steyn NP, Alberts M et al. (2002) Dietary intake and barriers to dietary compliance in black type 2 diabetic patients attending primary health-care services. Public Health Nutr 5, 329-338.

15. Vijan S, Stuart N, Fitzgerald J et al. (2005) Barriers to following dietary recommendations in Type 2 diabetes. Diabet Med 22, 32-38.

16. Funnell MM, Brown TL, Childs BP et al. (2009) National standards for diabetes self-management education. Diabetes Care 32, Suppl. 1, S87-S94.

17. Clark M (2008) Diabetes self-management education: a review of published studies. Prim Care Diabetes 2, 113-120.

18. Norris SL, Engelgau MM \& Narayan KV (2001) Effectiveness of self-management training in type 2 diabetes: a systematic review of randomized controlled trials. Diabetes Care 24, 561-587.

19. American Diabetes Association (2010) Position statement: Standards of medical care in diabetes - 2010. Diabetes Care 33, Suppl. 1, S11-S61.

20. Pastors JG, Warshaw H, Daly A et al. (2002) The evidence for the effectiveness of medical nutrition therapy in diabetes management. Diabetes Care 25, 608-613.

21. Clark M, Hampson SE, Avery L et al. (2004) Effects of a tailored lifestyle self-management intervention in patients with Type 2 diabetes. Br J Health Psychol 9, 365-379.

22. Shafer L, Gillespie A, Lynn Wilkins J et al. (1996) Position of the American Dietetic Association: nutrition education for the public. J Am Diet Assoc 96, 1183-1187.

23. Statistics South Africa (2012) Census 2011 Municipal ReportNorth West. Pretoria: Statistics South Africa.

24. Muchiri JW, Gericke GJ \& Rheeder P (2011) Needs and preferences for nutrition education of type 2 diabetic adults in a resource-limited setting in South Africa. Health $S A$ Gesonheid 17, 13.

25. Baranowski T, Perry CL \& Parcel GS (2002) How individuals, environments and health behaviour interact: Social Cognitive Theory. In Health Behaviour and Health Education Theory, Research and Practice, 3rd ed, pp. 165-184 [K Glanz, BK Rimer and FM Lewis, editors]. San Francisco, CA: Josey-Bass.

26. Baranowski T, Cullen KW, Nicklas T et al. (2003) Are current health behavioral change models helpful in guiding prevention of weight gain efforts? Obes Res 11, Suppl. 10, 23S-43S.

27. Institute of Medicine (2002) Dietary Reference Intakes: Energy, Carbohydrates, Fatty Acids, Cholesterol, Protein and Amino Acids. Washington, DC: National Academies Press.

28. Gill G, Price C, Shandu D et al. (2008) An effective system of nurse-led diabetes care in rural Africa. Diabet Med 25, 606-611.

29. Department of Health, Directorate of Nutrition (2004) South African Guidelines for Healthy Eating for Adults and Children Over the Age of Seven Years. Pretoria: Department of Health.

30 Keogh-Brown MR, Bachmann M \& Shepstone L (2007) Contamination in trials of educational intervention. Health Technol Assess 11, 43.

31. Lee RD \& Nieman DC (2007) Nutritional Assessment. Boston, MA: McGraw-Hill.

32. Atkinson B \& Veriava Y (2006) South African hypertension guideline 2006. S Afr Med J 96, 337-362.

33. Centers for Diseases Control and Prevention (2002) Measuring guides for the dietary recall interview 2002+ . http:// www.cdc.gov/nchs/nhanes/measuring_guides_dri/measuringguides02.htm (assessed January 2010).

34. Hollis S \& Campbell F (1999) What is meant by intention to treat analysis? Survey of published randomised controlled trials. BMJ 319, 670-674.

35. Koch GG, Carr GJ, Amara IA et al. (1990) Categorical data analysis. In Statistical Methodology in the Pharmaceutical Sciences, pp. 389-473 [DA Berry, editor]. New York: Marcel Dekker.

36. Bland JM \& Altman DG (1996) The use of transformation when comparing two means. BMJ 312, 1153.

37. Yannakoulia M, Poulia KA, Mylona E et al. (2007) Effectiveness of an intensive nutritional intervention in patients with type 2 diabetes mellitus: results from a pilot study. Rev Diabet Stud 4, 226-230.

38. Anderson-Loftin W, Barnett S, Bunn P et al. (2005) Soul food light: culturally competent diabetes ducation. Diabetes Educ 31, 555-563.

39. Miller CK, Edwards L, Kissling G et al. (2002) Nutrition education improves metabolic outcomes among older adults with diabetes mellitus: results from a randomized controlled trial. Prev Med 34, 252-259.

40. Deakin T, Cade J, Williams R et al. (2006) Structured patient education: the diabetes X-PERT programme makes a difference. Diabet Med 23, 944-954.

41. Shabbidar S, Fathi B \& Shirazifard NM (2006) Effects of clinical nutrition education on glycemic control outcomes in type 2 diabetes. Int J Diabetes Dev Count 26, 156-159.

42. Wolf AM, Conaway MR, Crowther JQ et al. (2004) Translating lifestyle intervention to practice in obese patients with type 2 diabetes: Improving Control with Activity and Nutrition (ICAN) study. Diabetes Care 27, 1570-1576.

43. Nestle M, Wing R, Birch L et al. (1998) Behavioural and social influences on food choice. Nutr Rev 56, 5 Pt 2, S50-S74.

44. Evert AB, Boucher JL, Cypress M et al. (2013) Nutrition therapy recommendations for the management of adults with diabetes. Diabetes Care 36, 3821-3842. 
45. Wilson C, Brown T, Acton K et al. (2003) Effects of clinical nutrition education and educator discipline on glycemic control outcomes in the Indian health service. Diabetes Care 26, 2500-2504.

46. Goldhaber-Fiebert JD, Goldhaber-Fiebert SN, Tristán ML et al. (2003) Randomized controlled community-based nutrition and exercise intervention improves glycemia and cardiovascular risk factors in type 2 diabetic patients in rural Costa Rica. Diabetes Care 26, 24-29.

47. Coppell KJ, Kataoka M, Williams SM et al. (2010) Nutritional intervention in patients with type 2 diabetes who are hyperglycaemic despite optimised drug treatment - Lifestyle Over and Above Drugs in Diabetes (LOADD) study: randomised controlled trial. BMJ 341, c3337.

48. Norris SL, Lau J, Smith SJ et al. (2002) Self-management education for adults with type 2 diabetes: a meta-analysis of the effect on glycemic control. Diabetes Care 25, 1159-1171.

49. Pastors JG, Franz MJ, Warshaw H et al. (2003) How effective is medical nutrition therapy in diabetes care? J Am Diet Assoc 103, 827-831.

50. Stratton IM, Adler AI, Neil HAW et al. (2000) Association of glycaemia with macrovascular and microvascular complications of type 2 diabetes (UKPDS 35): prospective observational study. BMJ 321, 405-412.

51. National Institute for Health and Clinical Excellence (2009) Type 2 Diabetes: Newer Agents for Blood Glucose Control in Type 2 Diabetes. NICE Short Clinical Guidelines. London: NICE.

52. Huang M-C, Hsu C-C, Wang H-S et al. (2010) Prospective randomized controlled trial to evaluate effectiveness of registered dietitian-led diabetes management on glycemic and diet control in a primary care setting in Taiwan. Diabetes Care 33, 233-239.

53. Norris SL, Zhang X, Avenell A et al. (2004) Long-term effectiveness of lifestyle and behavioral weight loss interventions in adults with type 2 diabetes: a meta-analysis. Am J Med 117, 762-774.

54. Sallé A, Ryan M \& Ritz P (2006) Underreporting of food intake in obese diabetic and nondiabetic patients. Diabetes Care 29, 2726-2727.

55. Olendziki BC, Ma Y, Hebert JR et al. (2008) Underreporting of energy intake and associated factors in a Latino population at risk of developing type 2 diabetes. J Am Diet Assoc 108, 1003-1008.

56. Ma Y, Olendziki BC, Merrima PA et al. (2008) A randomised clinical trial comparing low glycemic index versus ADA dietary education among individuals with type 2 diabetes. Nutrition 24, 45-56.
57. Brown SA, Garcia AA, Kouzekanani K et al. (2002) Culturally competent diabetes self-management education for Mexican Americans: the Starr County Border Health Initiative. Diabetes Care 25, 259-268.

58. Mayer-Davis EJ, D'Antonio AM, Smith SM et al. (2004) Pounds off with empowerment (POWER): a clinical trial of weight management strategies for black and white adults with diabetes who live in medically underserved rural communities. Am J Public Health 94, 1736-1742.

59. Amod A, Motala A, Levitt N et al. (2012) The 2012 SEMDSA Guideline for the management of type 2 diabetes. J Endocrinol Metab Diabetes S Afr 17, Suppl. 1, S1-S95.

60. Camelon KM, Hådell K, Jämsen PT et al. (1998) The plate model: a visual method of teaching meal planning. J Am Diet Assoc 98, 1155-1158.

61. Canadian Diabetes Association (2003) Zimbabwe Hand Jive. Can J Diabetes 27, Suppl. 2, S130.

62. Bantle JP, Wylie-Rosett J, Albright AL et al. (2008) Nutrition recommendations and interventions for diabetes: a position statement of the American Diabetes Association. Diabetes Care 31, Suppl. 1, S61-S78.

63. Wheeler ML, Dunbar SA, Jaacks LM et al. (2012) Macronutrients, food groups, and eating patterns in the management of diabetes: a systematic review of the literature, 2010. Diabetes Care 35, 434-445.

64. National Agricultural Marketing Council, Markets \& Economics Research Centre (2014) Food Price Monitor: February 2014. Pretoria: National Agricultural Marketing Council.

65. Shilts MK, Horowitz M \& Townsend MS (2004) Goal setting as a strategy for dietary and physical activity behavior change: a review of the literature. Am J Health Promot 19, 81-93.

66. Mishali M, Omer H \& Heymann A (2011) The importance of measuring self-efficacy in patients with diabetes. Fam Pract 28, 82-87.

67. Nyunt SW, Howteerakul N, Suwannapong N et al. (2010) Self-efficacy, self-care behaviors and glycemic control among type-2 diabetes patients attending two private clinics in Yangon, Myanmar. Southeast Asian J Trop Med Public Health 41, 943-951.

68. Howe A, Keogh-Brown M, Miles S et al. (2007) Expert consensus on contamination in educational trials elicited by a Delphi exercise. Med Educ Res 41, 196-204.

69. Nigam PK (2011) Serum lipid profile: fasting or non-fasting? Indian J Clin Biochem 26, 96-97. 